\title{
The LAT1 inhibitor JPH203 reduces growth of thyroid carcinoma in a fully immunocompetent mouse model
}

\author{
Pascal Häfliger ${ }^{1,4}$, Julien Graff ${ }^{2}$, Matthias Rubin ${ }^{1}$, Amandine Stooss ${ }^{1}$, Matthias S. Dettmer ${ }^{3}$, Karl-Heinz Altmann², \\ Jürg Gertsch ${ }^{1}$ and Roch-Philippe Charles ${ }^{1 *}$ (D)
}

\begin{abstract}
Background: The L-type amino acid transporter 1 (LAT1/SLC7A5) transports essential amino acids across the plasma membrane. While LAT1 is overexpressed in a variety of human neoplasms, its expression and its role in thyroid cancer is currently unknown. Anaplastic thyroid carcinoma (ATC) is a highly aggressive malignancy for which no effective therapy exists. The purpose of this study was to explore whether the inhibition of LAT1 in ATC would affect tumor growth both in vitro and in vivo.

Methods: LAT1 was pharmacologically blocked by JPH203 in human ATC and papillary thyroid cancer (PTC) cell lines. The effects on proliferation and MTORC1 activity were addressed in vitro. A genetically engineered mouse model of ATC was used to address the effect of blocking LAT1 on tumor growth in vivo. SLC7A5 transcription was measured in patient-derived ATC samples to address the clinical relevance of the findings.

Results: LAT1 block by JPH203 reduced proliferation and mTORC1 signaling in human thyroid cancer cell lines. SLC7A5 transcription was upregulated in ATC tissues derived from a genetically engineered mouse model and in ATC samples recovered from patients. JPH203 treatment induced thyroid tumor growth arrest in vivo in a fully immunocompetent mouse model of thyroid cancer. Additionally, analysis of publicly available datasets of thyroid carcinomas revealed that high LAT1 expression is associated with potentially untreatable PTC presenting reduced NIS/SLC5A5 transcription and with ATC.
\end{abstract}

Conclusions: These preclinical results show that LAT1 inhibition is a novel therapeutic approach in the context of thyroid cancers, and more interestingly in untreatable thyroid cancers.

Keywords: Genetically engineered mice, ATC, BRAF, SLC7A5, mTOR

\section{Background}

A major hallmark of cancer is sustained proliferative signaling [1], which allows cells to divide rapidly in an uncontrolled way. Proliferation is highly energy demanding and depends on the availability of nutrients in the tumor microenvironment. Among these nutrients, essential amino acids (EAA) require an active transport across the plasma membrane in order to be available for protein synthesis. The L-type amino acid transporter 1 (LAT1/

\footnotetext{
* Correspondence: roch-philippe.charles@ibmm.unibe.ch

${ }^{1}$ Institute of Biochemistry and Molecular Medicine, and Swiss National Center of Competence in Research (NCCR) TransCure, University of Bern, Bühlstrasse 28, CH-3012 Bern, Switzerland

Full list of author information is available at the end of the article
}

SLC7A5) is a membrane transporter for EAA such as leucine and phenylalanine. LAT1 functions in a $\mathrm{Na}^{+}$-independent manner [2] and exchanges glutamine for substrate EAA [3]. LAT1 is covalently attached to 4F2hc (also termed CD98 or SLC3A2), which is required for its trafficking to the membrane [4]. LAT1 is expressed in the brain endothelium, placenta and spleen $[2,5,6]$. Interestingly, LAT1 has been shown to be overexpressed during the development of a variety of different tumors such as prostate, breast, gastric, lung and pancreatic cancers [7-11]. It works in concert with ASCT2/SLC1A5 that effects inwards transport of glutamine and thus participates in establishing the glutamine gradient that is required for LAT1-dependent leucine uptake [3]. Likewise,

(C) The Author(s). 2018 Open Access This article is distributed under the terms of the Creative Commons Attribution 4.0 International License (http://creativecommons.org/licenses/by/4.0/), which permits unrestricted use, distribution, and 
ASCT2/SLC1A5 is also elevated in numerous cancers [12-14].

Thyroid cancer is the most frequent endocrine neoplasia and its incidence has dramatically increased during the past 30 years [15]. In 2016, thyroid cancer ranks fifth in the number of all estimated new cases of cancer in females in the US [16]. Papillary thyroid carcinoma (PTC) is the most frequent type, representing about $80 \%$ of all cases [17]. PTC is well managed in the clinic by thyroidectomy alone or complemented with radioactive iodine treatment with a 5-years survival rate of 94\% [18]. In contrast, patients that are diagnosed with anaplastic thyroid carcinoma (ATC), one of the most aggressive tumors known in humans, have a dismal prognosis with a median survival rate of 5 months and a 20\% 1-year survival [19]. Although ATC represents only about $2 \%$ of thyroid carcinoma [17], its invariable fatal outcome underscores that new therapeutic strategies are urgently needed to combat this highly aggressive disease.

BRAF is part of the RAS-RAF-MEK-ERK pathway, and is mutated in human cancers with a frequency of $8 \%$ [20]. More than $90 \%$ of BRAF mutations are caused by a $\mathrm{T} 1799 \mathrm{~A}$ transversion, resulting in $\mathrm{BRAF}^{\mathrm{V} 600 \mathrm{E}}$ mutant protein expression. In thyroid cancer, this mutation is found in $40 \%$ of the cases overall and $25 \%$ of ATC cases [21]. A conditional mouse model mimicking $\mathrm{BRAF}^{\mathrm{V} 600 \mathrm{E}}$ is able to initiate tumor formation in lung [22], melanocytes [23] and pancreas [24]. Regarding thyroid cancer, thyroid-specific $\mathrm{BRAF}^{\mathrm{V} 600 \mathrm{E}}$ expression leads to PTC in mice, thus confirming the importance of the mutation in this pathology [25]. Phosphoinositol 3 kinase (Pi3'K) mutations are frequent (23\%) in ATC [26]. When the activated mutant PIK3CA ${ }^{\mathrm{H} 1047 \mathrm{R}}$ is expressed in mice thyroids concomitantly with $\mathrm{BRAF}^{\mathrm{V} 600 \mathrm{E}}$, the progression from PTC to ATC resulting in mice death can occur within 3 to 6 months [27]. This model closely mimics the human ATC.

Despite previous associations between LAT1 and other cancer types, the role of LAT1 in thyroid cancer has not yet been studied. Here, we assessed whether LAT1 is upregulated during the progression of thyroid cancer and whether the inhibition of LAT1 by a potent and selective LAT1 inhibitor would reduce thyroid cancer growth both in vitro and in vivo. Our data show that LAT1 is highly expressed in human thyroid cancer cell lines and that LAT1 inhibition by JPH203 reduces proliferation and impairs mTORC1 activity. In vivo, JPH203 exerted a stalemate of tumor burden increase in a mouse model of thyroid cancer. In line with these findings, SLC7A5 transcription was elevated in human PTC samples and even further increased in ATC samples compared to normal thyroid tissues. In PTC, SLC7A5 level was found associated with worse prognosis and reduced SLC5A5 (Sodium iodine symporter) transcription. This is the first study showing a critical role for LAT1 in a solid tumor in a genetically engineered mouse model baring fully competent immune system. LAT1 inhibition in highly aggressive thyroid cancers might be a novel therapeutic strategy to stop tumor growth in thyroid cancer patients.

\section{Methods \\ $\mathrm{JPH} 203$}

JPH203 was synthesized following the route described in ref. [28]. The analytical data for all intermediates and JPH203 $\left({ }^{1} \mathrm{H}\right.$-NNMR, ${ }^{13} \mathrm{C}$-NMR, ${ }^{18} \mathrm{~F}$-NMR, where applicable) were in agreement with the expected structures. The analytical data for JPH203 are included in the SI.

\section{Animals}

All animal experiments were in accordance with the Swiss animal welfare law and were approved by the local veterinary authority in Bern (license number: BE92/15). $\mathrm{Braf}^{C A}$, Pik3ca ${ }^{\text {Lat }}$ and Thyro::Cre $e^{E R T 2}$ mice were described previously [22, 25, 27, 29]. Thyrocyte-specific $\mathrm{Cre}^{\mathrm{ERT} 2}$ activation was achieved by intraperitoneal injection of $1 \mathrm{mg}$ of tamoxifen dissolved in $100 \mu \mathrm{l}$ of peanut oil into 5-7 weeks old mice for five consecutive days.

\section{MEK/PI3K inhibition in mice}

Double mutant BRAF $^{\mathrm{V} 600 \mathrm{E}}$ PIK3CA ${ }^{\mathrm{H} 1047 \mathrm{R}}$ mice, two months after tamoxifen injections were treated by oral gavage with $5 \mathrm{mg} / \mathrm{kg}$ of PD-325901 or $50 \mathrm{mg} / \mathrm{kg}$ of GDC-0941, formulated in Hydroxypropyl methylcellulose $0.5 \%$, Tween- $800.2 \%$ for 10 consecutive days. Vehicle only was used as a control. Tumours were resected $4 \mathrm{~h}$ after the last gavage and snap frozen prior to RNA extraction. Small drug inhibitors were purchased from Abmole.

\section{Cell lines}

8505c cells were purchased from ECACC (cat. no. 94090184), LNCaP cells were purchased from Sigma-Aldrich (cat. no. 89110211), SW1736 cells were purchased from CLS (cat. no. 300453). Hth104, KTC1 and TPC-1 cells were a gift from Prof. James Fagin (MSKCC, New York, USA) and were cultured in RPMI medium (Sigma-Aldrich, cat. no. R8758). K1 cells were a gift from Prof. James Fagin (MSKCC, New York, USA) and cultured in DMEM:F12 medium (Gibco, cat. no. 11320-074). HT-29 cells were purchased from ATCC (cat. no. HTB-38) and cultured in Modified McCoy's 5A medium (Gibco, cat. no. 26600-080). Media of all cell lines were supplemented with 10\% FBS (Gibco, cat. no.10270), $100 \mathrm{U} / \mathrm{ml}$ penicillin (Sigma-Aldrich, cat. no. P0781), $0.1 \mathrm{mg} / \mathrm{ml}$ streptomycin (Sigma-Aldrich, cat. no. P0781). Media of 8505c, LNCaP and K1 cells were additionally supplemented with $1 \mathrm{X}$ Non-Essential Amino Acids (NEAA) (BioConcept, cat. no. 5-13 K00). All cell 
lines were kept up to 50 passages or 6 months, whichever limit was reached first.

\section{Patients}

The use of PTC and ATC patient histological tissue sections obtained at the University Hospital of Bern (Inselspital) was approved by the Cantonal Ethics Committee Bern (ref. no. 200/2014). Histological diagnosis was performed by one of the authors (M.S. D.).

\section{Real-time PCR}

Total RNA from cells and mouse thyroid tissue was extracted by using Qiazol reagent (Qiagen, cat. no. 79306) according to the manufacturer's protocol. Total RNA from formalin-fixed paraffin-embedded human thyroid cancer tissue was extracted using a High Pure FFPET RNA isolation kit (Roche, cat. no. 06868517001) according to the manufacturer's protocol. Reverse-transcription was performed with Superscript II (Invitrogen, cat. no. 18064-014) following the manufacturer's protocol. TaqMan real-time primer/probe sets were purchased from Applied Biosystems: Slc7a5 Mm00441516_m1, SLC7A5 Hs00185826_m1, Slc3a2 Mm00500521_m1, Slc1a5 Mm 00436603_m1, Slc38a2 Mm00549967_m1, Atf5 Mm0417 9654_m1, actb 4352341E, Tuba1a Mm00846967_g1, $A C T B$ 4326315E. Quantifications were performed using a ViiA 7 real-time PCR machine (Applied Biosystems). Relative differences in gene expression levels were assessed by normalizing the $\mathrm{Ct}$ value of the target gene to the $\mathrm{Ct}$ value of the housekeeping gene and quantified by the $2^{-\Delta \Delta \mathrm{Ct}}$ method.

\section{Western blotting}

Proteins were extracted in RIPA buffer $(20 \mathrm{mM}$ Tris-base pH 8, $150 \mathrm{mM} \mathrm{NaCl}, 1 \%$ Triton X-100, 0.1\% SDS, $0.5 \%$ sodium deoxycholate) supplemented with Halt protease/phosphatase inhibitor cocktail (Pierce, cat. no. 78444). Protein concentration was assessed by Pierce BCA protein assay kit (Thermo Scientific, cat. no. 23225) and 10-30 $\mu \mathrm{g}$ total protein were separated by SDS-PAGE. Protein gels were transferred onto nitrocellulose membranes and blocked in 5\% BSA in TBS. Primary antibody used (purchased from Cell signaling unless specified): P-p70S6K (cat. no. 2708), p70S6K (cat. no. 2708) P-S6 S240/244 (cat. no. 5364), P-S6 S235/236 (cat. no. 4858), S6 (cat. no. 2217), P-ERK (cat. no. 9107), Tot-ERK (cat. no. 4370), P-AKT S473 (cat. no. 4060), pan-AKT (cat. no. 2920), ß-actin (Sigma-Aldrich, cat. no. A5316) and LAT1 (TransGenic Inc., cat. no. KE026). Primary antibodies were detected by using goat anti-rabbit IR680 (Li-Cor Bioscience, cat. no. 926-68071) and goat anti-mouse IR800 (Li-Cor Bioscience, cat. no. 926-32210) and imaged by a LI-COR OdysseySA imaging system.

\section{Proliferation assays}

Cells were seeded at $10 \%$ confluency in a 96-well plate. They were allowed to adhere overnight, washed once with PBS and incubated in custom media: Earle's balanced salt solution (EBSS) plus $5.5 \mathrm{mM}$ D-glucose, $0.025 \mathrm{mM}$ phenol red (Gibco, cat. no. 24010-043), 10\% FBS, $100 \mathrm{U} / \mathrm{ml}$ penicillin, $0.1 \mathrm{mg} / \mathrm{ml}$ streptomycin, $2 \mathrm{mM}$ L-glutamine, 1X NEAA (BioConcept, cat. no. 5-13 K00) and 1X MEM vitamin solution (Gibco, cat. no. 11120-052). For proliferation assays at different concentrations of essential amino acids (EAA), medium described above was supplemented with $1 \mathrm{X}$ MEM amino acids solution (Gibco, cat. no. 11130051; see Additional file 1: Table S1 for detailed composition) and a two-fold serial dilution with the EAA-free medium was performed. Dose-response curves were carried out in custom medium with 0.125X MEM amino acids solution (Table S1). LNCaP wells were coated overnight with $0.1 \mathrm{mg} / \mathrm{ml}$ poly-D-lysine (Sigma-Aldrich, cat. no. P6407-5MG) in order to avoid detachment during washings. Cells were treated with the indicated concentration of JPH203 for two population doubling times ( $48 \mathrm{~h}$ for $8505 \mathrm{c}, \mathrm{SW} 1736$ and $\mathrm{K} 1 ; 96 \mathrm{~h}$ for LNCaP) and fixed with $10 \%$ buffered formalin, stained with $0.2 \%$ crystal violet (Sigma-Aldrich, cat. no. C3886-25G) in 2\% ethanol, washed 5 times in $\mathrm{dH}_{2} \mathrm{O}$ and lysed with $100 \mu \mathrm{L} 1 \%$ SDS. OD at $550 \mathrm{~nm}$ was measured with a microplate reader and normalized to DMSO control.

\section{Ultrasound imaging and JPH203 treatment in vivo}

Tumor burden was measured by quantifying the area of the largest thyroid cross-section observed $\left(\mathrm{mm}^{2}\right)$ and normalized to the size at the beginning of the experiment as described previously [30]. JPH203 was diluted in $40 \%(w / v)$ Captisol $^{\circ}$ (CyDex Pharmaceuticals) at a concentration of $7.5 \mathrm{mg} / \mathrm{ml}$ and sonicated for $1 \mathrm{~min}$. Mice were treated for 5 consecutive days/week for 45 days with $200 \mu \mathrm{l}$ of $7.5 \mathrm{mg} / \mathrm{ml} \mathrm{JPH} 203$ or vehicle by i.p. injection, corresponding to a dose of $50 \mathrm{mg} / \mathrm{kg} /$ day.

\section{Immunofluorescence staining and TUNEL}

Tissue section and Tunel stains were performed as described before [30]. Primary antibodies anti-Ki67 (Abcam cat. no. ab16667,) and anti-BrdU (Abcam cat. no. ab6326, ) were incubated overnight at $4{ }^{\circ} \mathrm{C}$. Secondary antibodies goat anti-rabbit Alexa-488 (Invitrogen, cat. no. A11034,) and goat anti-rat Alexa-555 (Invitrogen, cat. no. A21434,) were used to detect antigen-antibody complexes; slides were counter -stained with DAPI $(500 \mathrm{ng} / \mathrm{ml}$, Sigma Aldrich, cat. no. 32670-25MG). 


\section{Slides scanning}

Slides were scanned using a Pannoramic Midi digital slide scanner (3DHISTECH Ltd.) and analyzed by CellQuant software (3DHISTECH Ltd.). To quantify Ki67/ BrdU positive cells, an average of 8 nonconsecutive sections of the tumor were used for each sample, 4 sections for TUNEL.

\section{${ }^{3} \mathrm{H}$-leucine uptake assay}

Cells were seeded at $60 \%$ confluency in a 96 -well plate using complete culture medium and cultured until confluent. Cells were washed three times with $37{ }^{\circ} \mathrm{C}$ pre-warmed $\mathrm{Na}^{+}$-free Hank's balanced salt solution (HBBS) containing $125 \mathrm{mM}$ choline-Cl, $25 \mathrm{mM}$ HEPES, $4.8 \mathrm{mM} \mathrm{KCl}, 1.2 \mathrm{mM} \mathrm{MgSO}_{4}, 1.2 \mathrm{mM} \mathrm{KH}_{2} \mathrm{PO}_{4}, 1.3 \mathrm{mM}$ $\mathrm{CaCl}_{2}$ and $5.6 \mathrm{mM}$ glucose $(\mathrm{pH} 7.4)$ and further incubated in the same buffer at $37{ }^{\circ} \mathrm{C}$ for $7 \mathrm{~min}$. L-leucine uptake was measured for $3 \mathrm{~min}$ at $37{ }^{\circ} \mathrm{C}$ in the same buffer containing $30 \mu \mathrm{M} \mathrm{L}-\left[{ }^{3} \mathrm{H}\right]$ leucine $(60 \mathrm{Ci} / \mathrm{mmol})$ and different concentrations of JPH203. Uptake was terminated by removing the solution followed by three washings with ice-cold $\mathrm{Na}^{+}$-free HBBS. Cells were lysed and mixed with Microscint20 (Perkin-Elmer Life Sciences). The radioactivity was measured with a scintillation counter (TopCount NXT, Perkin-Elmer Life Sciences).

\section{${ }^{3} \mathrm{H}$-leucine efflux assay}

The same protocol as for the uptake was used with the following differences after the initial washing- and starvation-step. Cells were preloaded for 5 min at $37{ }^{\circ} \mathrm{C}$ in the $\mathrm{Na}^{+}$-free HBBS containing $30 \mu \mathrm{M} \mathrm{L}-\left[{ }^{3} \mathrm{H}\right]$ leucine $(60 \mathrm{Ci} / \mathrm{mmol})$. After washing three times with $\mathrm{Na}^{+}$-free HBBS $\left(4{ }^{\circ} \mathrm{C}\right)$, efflux of radioactivity was induced by incubation in the presence or absence of indicated concentrations of test compounds for $1.5 \mathrm{~min}$ at $37{ }^{\circ} \mathrm{C}$. The medium was then collected and its radioactivity was counted. The cells were washed three times with ice-cold $\mathrm{Na}^{+}$-free HBBS. Cells were lysed and mixed with Microscint20 (Perkin-Elmer Life Sciences). The radioactivity was measured with a scintillation counter (TopCount NXT, Perkin-Elmer Life Sciences). The $\mathrm{L}-\left[{ }^{3} \mathrm{H}\right]$ leucine efflux values were expressed as percentage radioactivity (radioactivity of medium)/(radioactivity of the medium + radioactivity of the cells)).

\section{Statistical analysis}

Data are expressed as average \pm SD. Statistical analyses were conducted using GraphPad Prism 7 (GraphPad Software). $\mathrm{IC}_{50}$ and $\mathrm{IG}_{50}$ values were calculated by nonlinear regression. Proliferation assays at different amino acid concentrations were analyzed by multiple t-test with Holm-Sidak correction. Transcript levels of amino acid transporters in thyroid tumors were analyzed with a
Kruskal-Wallis test with Dunn's correction. Drug-induced Slc7a5 reduction was analysed by an ordinary one-way ANOVA test. Tumor growth in vivo was analyzed with a two-way ANOVA test with Bonferroni correction. Proliferation and apoptosis markers of tumors were compared with a two-tailed Mann-Whitney test. Patient survival was analyzed with a log-rank test. Gene co-occurrence analysis was analyzed with a one-sided Fisher's exact test. $P \leq 0.05$ was considered as statistically significant; ${ }^{*}=p<0.05$, *** $=$ $p<0.01,{ }^{* * * *}=p<0.001$.

\section{Results}

\section{Expression and functional characterization of LAT1 in thyroid cancer cell lines}

SLC7A5 transcripts were found in all 6 thyroid cancer cell lines tested (Fig. 1a) with variable levels. In the HT-29 colon carcinoma cell line, SLC7A5 transcription was 8-fold higher compared to $\mathrm{K} 1$ (used as basal level = $1)$, whereas in the prostate cancer cell line LNCaP, SLC7A5 transcripts were undetectable (Fig. 1a).

We next evaluated LAT1 expression by western blotting. The specificity of the antibody employed was confirmed by the absence of signal in LNCaP cells and a strong signal in HT-29 cells (Fig. 1b). LAT1 expression was found in all cell lines with TPC-1 expression the highest level and $\mathrm{K} 1$ the lowest.

To explore the effects of blocking leucine transport through LAT1 in thyroid cancer cell lines we synthesized the highly specific LAT1 inhibitor JPH203 [31]. ${ }^{3} \mathrm{H}-$ leucine uptake was measured for 8505c, SW1736 and HT-29 cells in the presence of different concentrations of JPH203 (Fig. 1c). HT-29 cells served as positive control. The $\mathrm{IC}_{50}$ values for each cell line are summarized in Fig. 1d. ${ }^{3} \mathrm{H}$-leucine uptake was not affected by JPH203 in LNCaP (Additional file 1: Figure. S1), in agreement with the lack of LAT1 expression in these cells. To better understand the mechanism of action of JPH203 we compared its effect on ${ }^{3} \mathrm{H}$-leucine efflux to L-tyrosine and L-leucine, which are both substrates [32]. As shown in Fig. 1e, JPH203 behaves as a non-substrate and possibly competitive inhibitor of LAT1, which prevents the efflux of ${ }^{3} \mathrm{H}$-leucine induced by leucine and tyrosine.

\section{JPH203 effect on cell proliferation is dependent on EAA concentration and LAT1 expression}

The concentration of most EAAs in conventional media (Table S1) greatly exceeds the level found in plasma (supplementary data of [33]). In order to mimic physiological leucine concentration we prepared a customized culture medium that contained various concentrations of EAA in fractions of the standard cell culture levels (1X EAA). JPH203 at $10 \mu \mathrm{M}$ did not reduce cell proliferation at $1 \mathrm{X}$ EAA (Fig. 2) in any cell lines. However, when EAA 
A

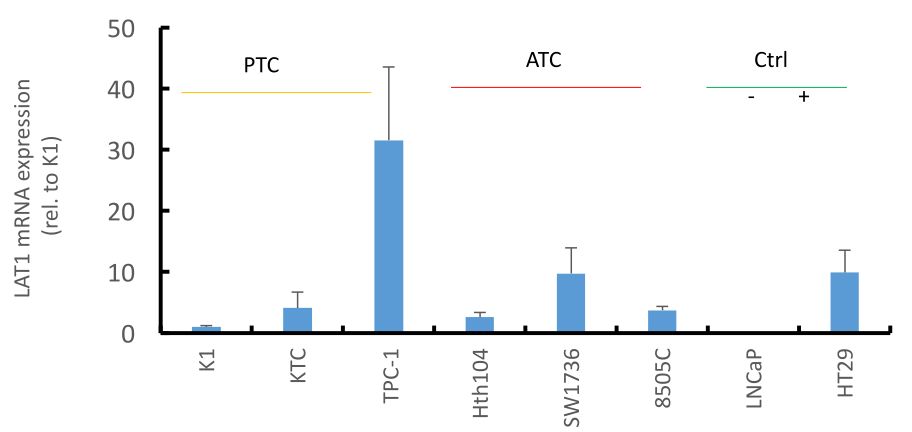

B

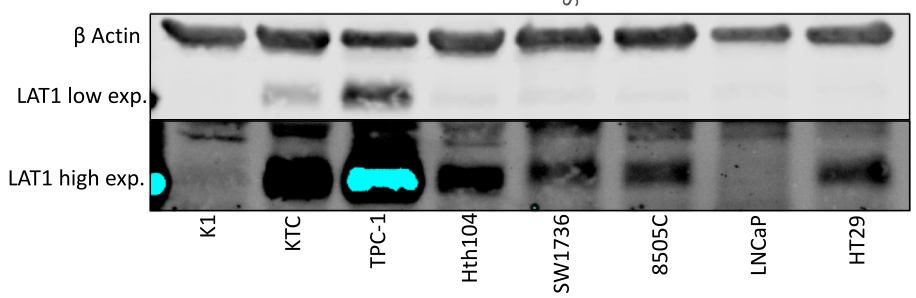

C

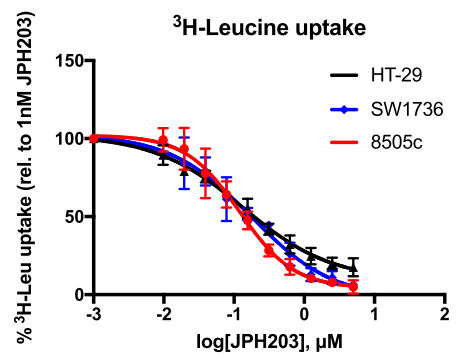

E

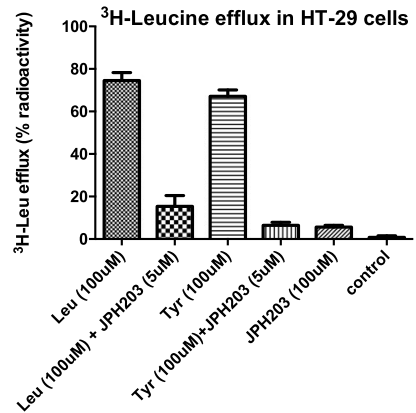

D

\begin{tabular}{cc} 
cell line & IC $_{\mathbf{5 0}}(\boldsymbol{\mu M})$ \\
\hline HT-29 & 0.134 \\
SW1736 & 0.177 \\
8505c & 0.120 \\
\hline
\end{tabular}

Fig. 1 LAT1 is highly expressed in ATC cell lines and JPH203 inhibits leucine uptake. a SLC7A5 transcription levels were quantified by Real-time PCR in three PTC cell lines (K1, KTC1, TPC-1) and three ATC cell lines (8505c, SW1736, Hth104). HT-29 cells served as positive control and LNCaP cells as negative control. LAT1 transcription levels were normalized to $\beta$-actin and plotted as fold change relative to K1 transcription level. b: LAT1 protein expression was quantified by western blotting in the cell lines described in (a). HT-29 cells served as positive control and LNCaP cells as negative control to confirm antibody specificity. Integrated signal of the LAT1 band was normalized to $\beta$-actin and displayed as fold change relative to K1. ${ }^{3} \mathrm{H}$-Leucine uptake assay was performed in 8505C, SW1736, and HT-29. Dose-response curve was conducted in triplicate and ${ }^{3} \mathrm{H}$-Leucine uptake at each concentration was normalized to the uptake at the lowest JPH203 concentration (1 nM). These results represent the average of three independent experiments. $\mathbf{d} I C_{50}$ values for each cell line were calculated from (c). (e): Efflux of preloaded $L-\left[{ }^{3} H\right]$ leucine induced by the two substrates leucine and tyrosine, and the inhibitor JPH203. The efflux of preloaded L-[ $\left.{ }^{3} \mathrm{H}\right]$ leucine was measured for $1.5 \mathrm{~min}$ in the presence or absence (control) of extracellularly applied substrates (100 $\mu \mathrm{M}$ leucine or tyrosine) and/or inhibitor (5 $\mu \mathrm{M}$ or $100 \mu \mathrm{M}$ JPH203). The radioactivity released from the cells was expressed as percent of the total preloaded radioactivity (\% radioactivity). Leucine efflux of the control (30-40\% radioactivity over all experiments) was set as $0 \%$ radioactivity and the samples were normalized to the control

concentrations were reaching plasma level (between $0.25 / 0.125 \mathrm{X}$ EAA), the proliferation of $8505 \mathrm{c}$ (Fig. 2a) and SW1736 cells (Fig. 2b) was significantly reduced by JPH203, while neither K1 nor LNCaP proliferation was significantly affected even at low concentrations of EAA (Fig. 2c and d ) by this $10 \mu \mathrm{M}$ dose of JPH203. Dose-response inhibition curves of JPH203 were then performed in medium supplemented with $0.125 \mathrm{X}$ EAA. K1 


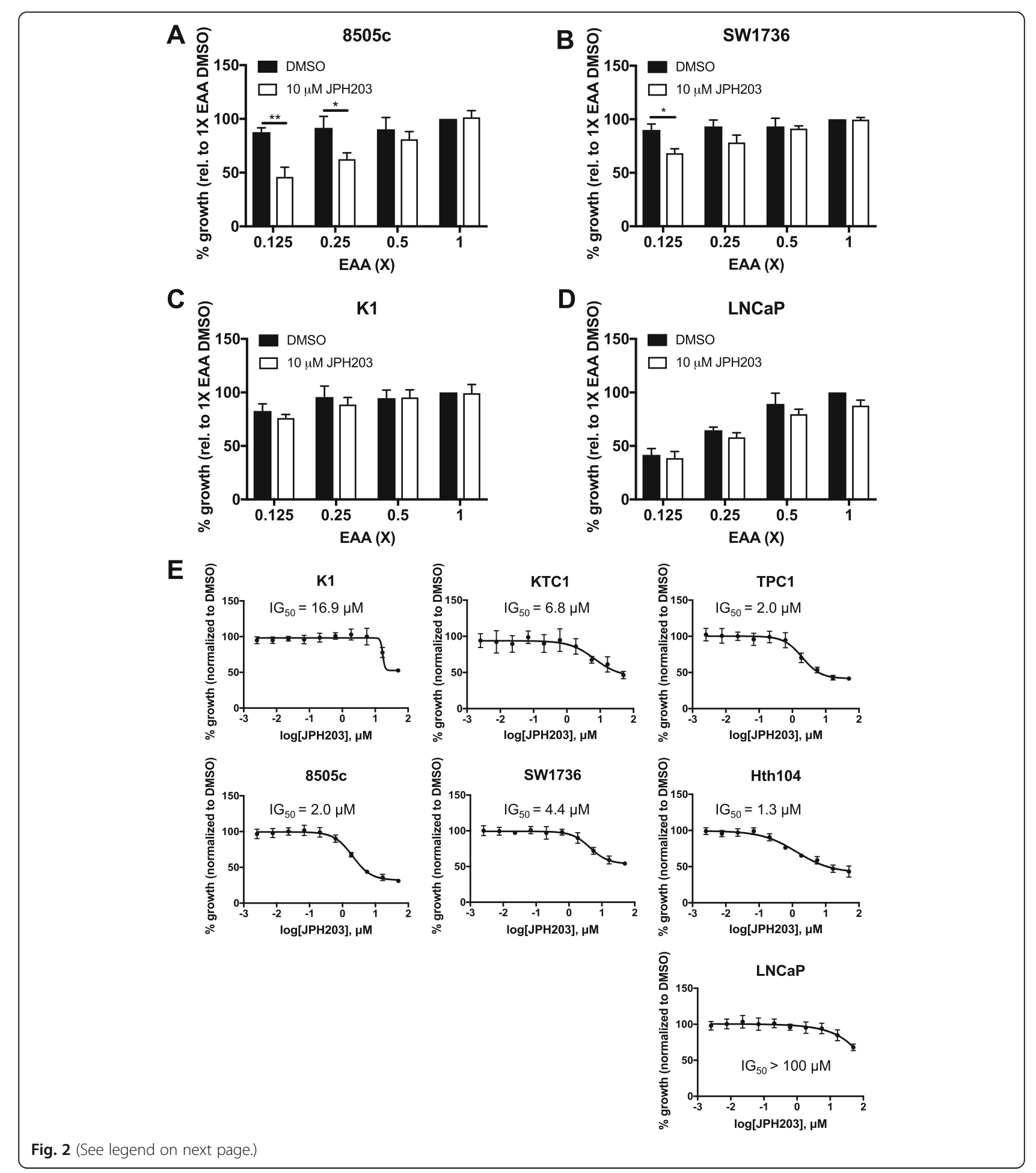


(See figure on previous page.)

Fig. $2 \mathrm{JPH} 203$ reduces proliferation of the ATC cell lines 8505C and SW1736 when EAA concentrations in medium were lowered to plasma level. Proliferation assays of two ATC cell lines (a) 8505c and (b) SW1736, the PTC cell line (c) K1 and (d) LNCaP cells as negative control were performed at different EAA concentrations (1X - 0.125X, see Table S1 for detailed composition). Cells were plated in sixplicate using normal growth medium, after overnight incubation cells were washed with PBS and medium containing specific EAA concentration was added. Cells were treated (DMSO/10 $\mu \mathrm{M}$ JPH203) and fixed after (a-c) $48 \mathrm{~h}$ or (d) $96 \mathrm{~h}$ (two population doubling times). Each condition was normalized to the proliferation of DMSO-treated 1X EAA. These results represent the average of three independent experiments. Statistical analysis was performed by using multiple t-tests, one per row, and Holm-Sidak correction for multiple comparisons. e Dose-response curves for JPH203 were conducted with three PTC cell lines (K1, KTC1, TPC-1) and three ATC cell lines (8505c, SW1736, Hth104) and LNCaP cells as a negative control using medium containing 0.125X EAA (see Table S1 for detailed composition). Cells were plated in triplicate using normal growth medium, after overnight incubation cells were washed with PBS and 0.125X EAA was added. Cells were treated with different concentrations of JPH203 between 2.5 nM and $50 \mu \mathrm{M}$ or DMSO as control. 8505c, SW1736, Hth104, KTC1, TPC-1 and K1 cells were incubated for 48 h; LNCaP cells for 96 h (two population doubling times) and growth was normalized to DMSO. These results represent the average of three independent experiments.

cells were the least sensitive with a relative $\mathrm{IG}_{50}$ of $16.9 \mu \mathrm{M}$ (Fig. 2e) while the three ATC cell lines and the PTC cell line TPC1 presented higher sensitivity to the drug with relative IG50 ranging between 1.3 and 4.4 $\mu$ M. Furthermore, in LAT1-negative LNCaP cells the relative $\mathrm{IG}_{50}$ was extrapolated from the curve to be over $100 \mu \mathrm{M}$ (Fig. 2e).

\section{LAT1 inhibition affects mTORC1 signaling}

Since LAT1 participates in mTORC1 activity [3] we measured Phospho-p70S6K and Phospho-S6 levels as a readout of mTORC1 in JPH203-treated cells. Both levels were significantly decreased in all thyroid cancer cell lines tested by $10 \mu \mathrm{M}$ JPH203 when cultured in $0.125 \mathrm{X}$ EAA medium (Fig. 3a and b). In LNCaP cells, JPH203

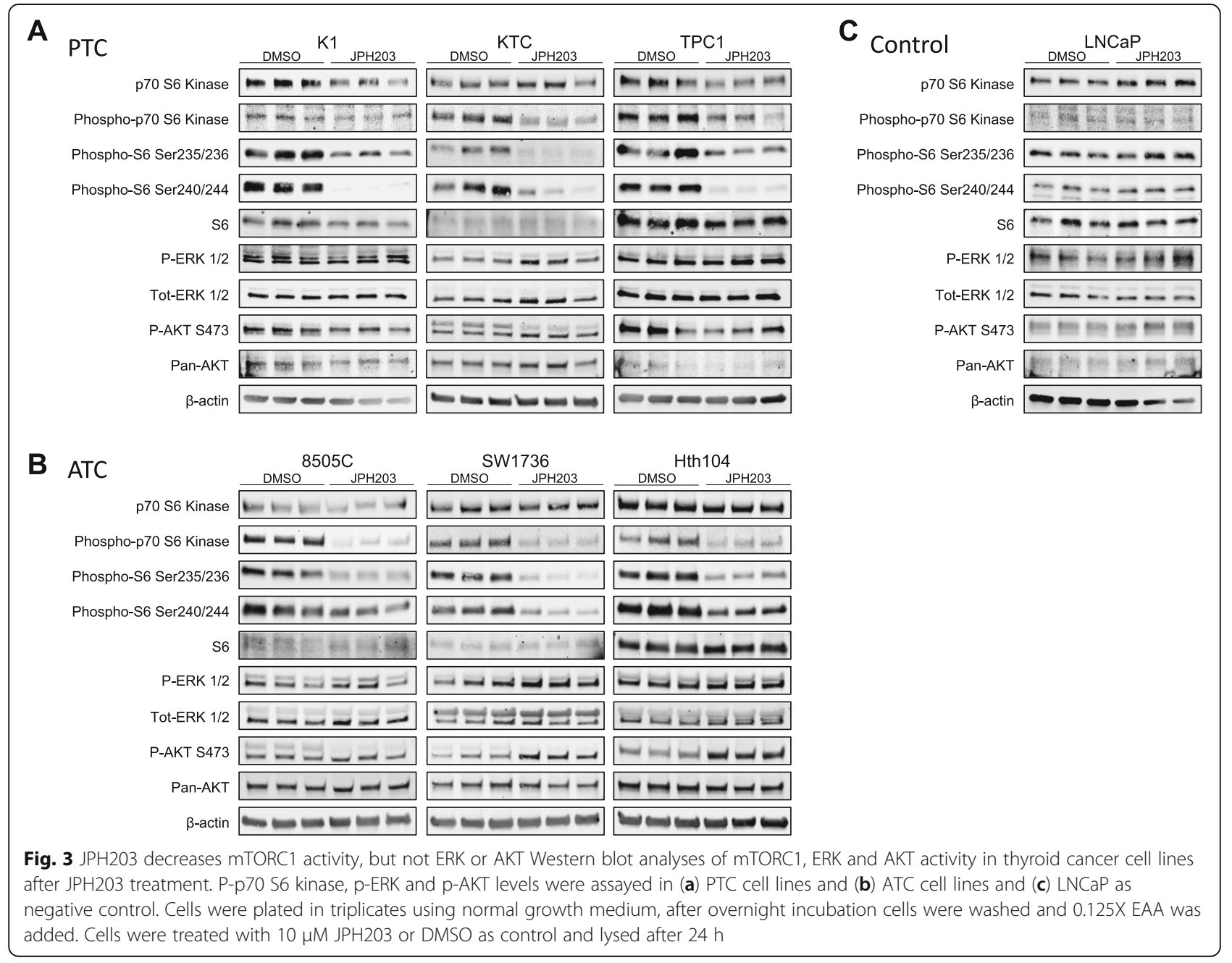


did not alter p-S6 levels consistently under these conditions (Fig. 3c). The ERK pathway was not altered by this treatment in any cells. AKT phosphorylation was not reduced and sometimes further elevated (SW1736 in Fig 3).

\section{Blocking LAT1 exerts a strong cytostatic effect on thyroid cancer growth in vivo}

Next, we investigated whether LAT1 was upregulated during the development of thyroid cancer in our mouse model [27]. Interestingly, Slc7a5 and Slc3a2 transcript levels were both significantly increased in $\mathrm{BRAF}^{\mathrm{V} 600 \mathrm{E}} / \mathrm{PIK} 3-$ $\mathrm{CA}^{\mathrm{H} 1047 \mathrm{R}}$ double-mutant tumors (4.8-fold and 2.3-fold, respectively) compared to wild-type samples. In $\mathrm{BRAF}^{\mathrm{V} 600 \mathrm{E}}$ single-mutant samples there was a tendency of increased Slc7a5 and Slc3a2 transcript levels, however this was not statistically significant (Fig. 4a). Slc1a5 encoding ASCT2, which fuels the glutamine gradient necessary for LAT1 activity, was not found elevated in both single- and double-mutant tumors. Interestingly, the surrogate transporter SNAT2 encoded by Slc38a2, which is a sodium -dependent glutamine transporter, was 2.2-fold upregulated in $\mathrm{BRAF}^{\mathrm{V} 600 \mathrm{E}} / \mathrm{PIK} 3 \mathrm{CA}^{\mathrm{H} 1047 \mathrm{R}}$ double-mutant tumors, which was close to being statistically significant $(p=0.0571$, Fig. 4a). The mouse model was therefore shown to be suitable to explore if blocking LAT1 would affect thyroid cancer growth in vivo.
Slc7a5 transcription has been shown to be driven by c-MYC [34]. We therefore tested if it was indeed the case in our model. BRAF ${ }^{\mathrm{V} 600 \mathrm{E}} / \mathrm{PIK} \mathrm{CA}^{\mathrm{H} 1047 \mathrm{R}}$ double -mutant Mice, two months after tumor induction, were treated with either a MEK inhibitor (PD-325901) and a class I Pi3'K inhibitor (GDC-0941) for ten days prior to dissection and LAT1 transcription analysis (Fig. 4b). While Pi3'K inhibition did not induced any change in Slc7a5 transcript abundance, MEK inhibition induced more than $50 \%$ reduction.

Thyroid tumorigenesis was induced in 6-weeks old adult $\mathrm{Braf}^{\mathrm{CA} /{ }_{+}}$;Pik3ca ${ }^{\mathrm{Lat} /+}$; Thyro::Cre ${ }^{E R T 2}$ mice by tamoxifen injection, which results in thyrocyte-specific expression of $\mathrm{BRAF}^{\mathrm{V} 600 \mathrm{E}}$ and PIK3CA ${ }^{\mathrm{H} 1047 \mathrm{R}}$. A cohort of 12 mice was separated into two groups that were treated with either vehicle or $50 \mathrm{mg} / \mathrm{kg} \mathrm{JPH} 203$ i.p. daily for five days per week during 6.5 weeks (Fig. 5a). Weekly ultrasound imaging revealed that JPH203 exerted an arrest of tumor growth already after 14 days of treatment, whereas tumors of vehicle-treated mice continued to grow until the end of the experiment (Fig. 5c). Representative images comparing the tumor burden at day 45 (end of the study) to day 0 (start of treatment) illustrate the significant difference between vehicle- and JPH203 -treated mice (Fig. 5b). In this model of thyroid cancer, all thyrocytes are undergoing recombination and

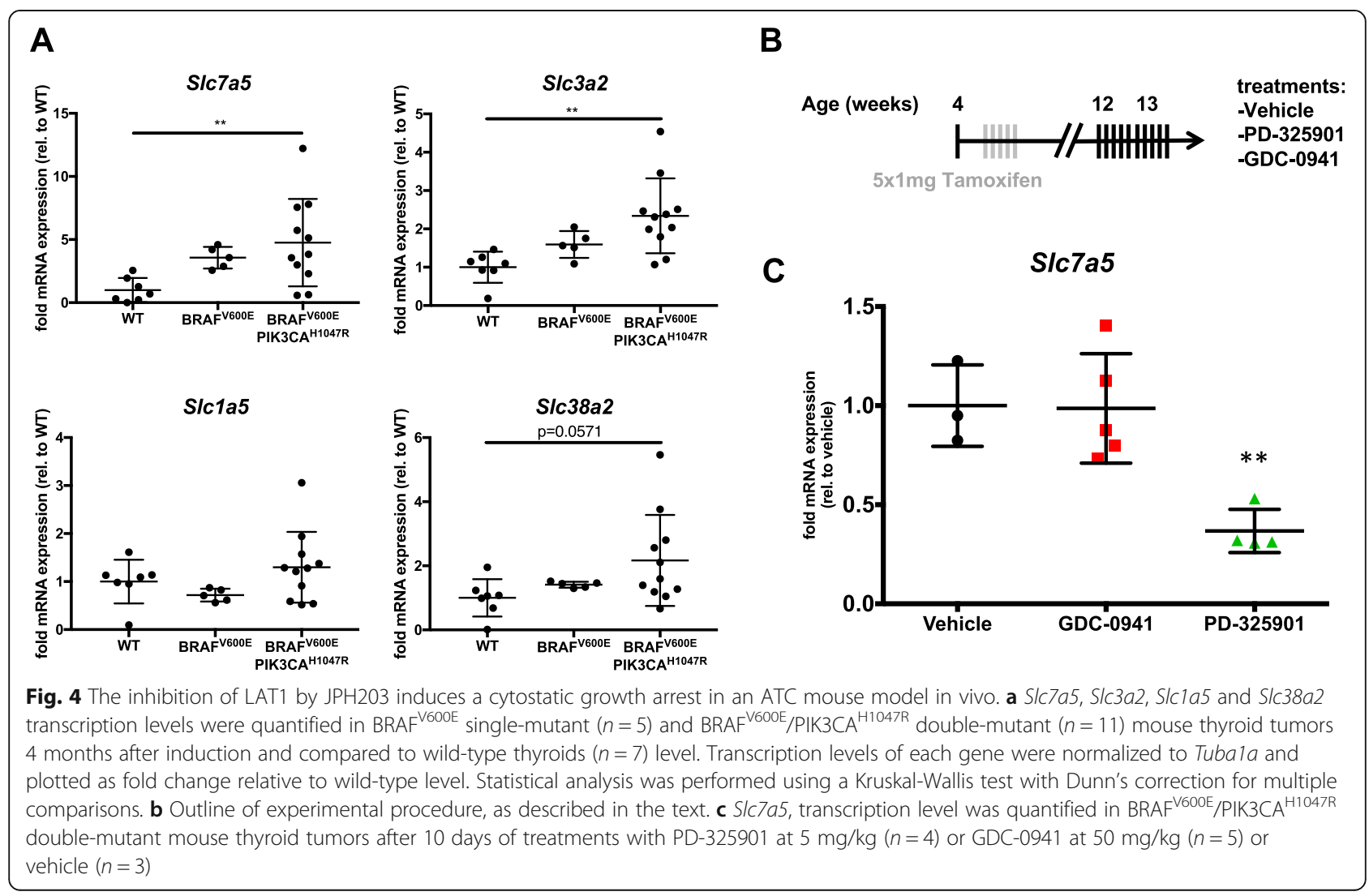




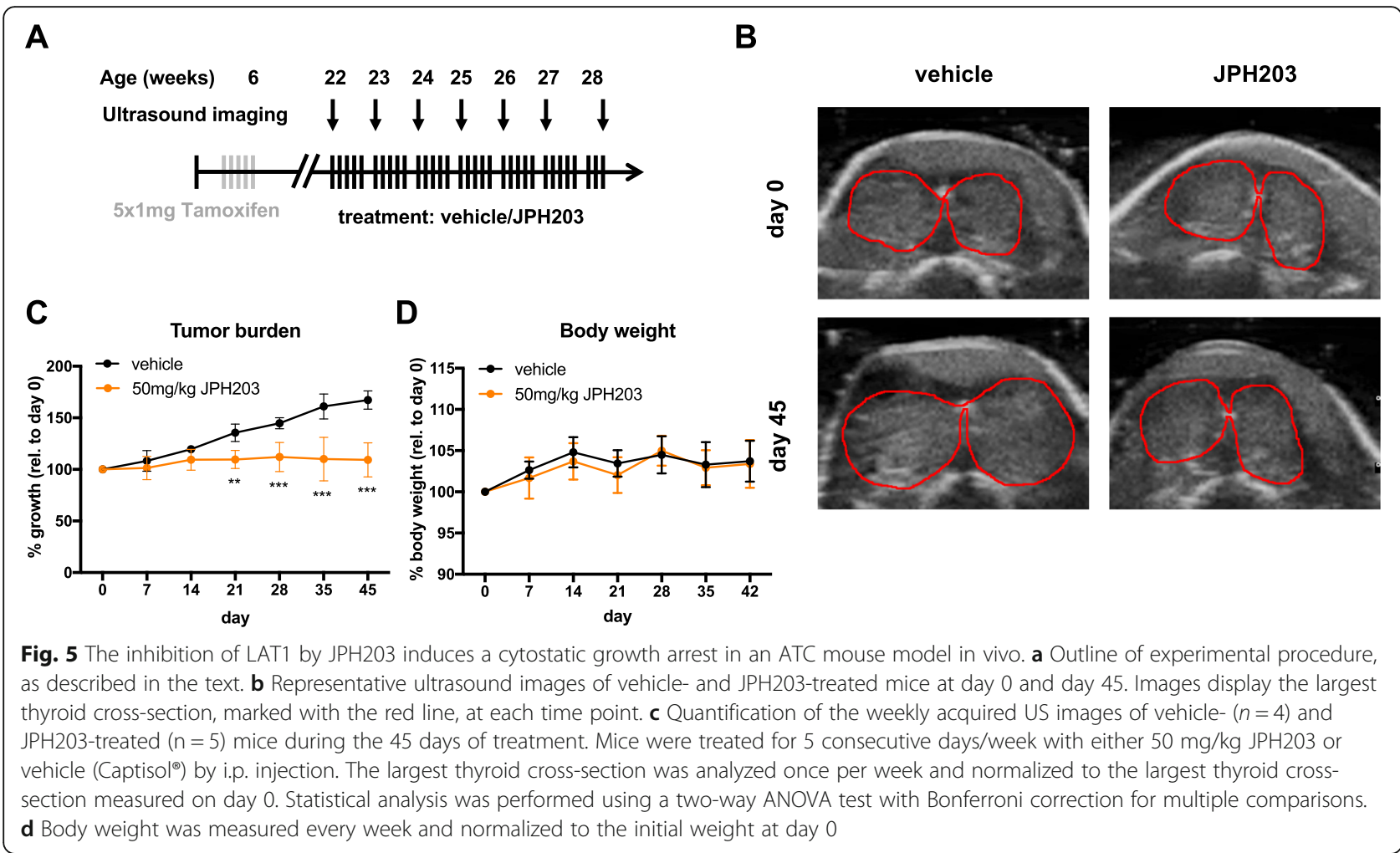

transformation, inducing a cancerization of the whole thyroid. Therefore the assessment of whole thyroid size for tumor burden was used. Three mice (2 in the vehicle group, 1 in the JPH203 group) were excluded from the evaluation of the experiment, because they reached thyroid cancer-related end-point criteria (sudden >15\% bodyweight loss) before the end of the study. There was otherwise no difference in body weight between vehicleand JPH203-treated mice (Fig. 5d). This suggests that JPH203 treatment has no striking adverse effects at the dosage employed (50 mg/kg i.p.).

\section{LAT1 inhibition increased TUNEL-positive nuclei and activated the amino acid stress response in thyroid tumors in vivo}

Hematoxylin/Eosin stains of thyroid sections revealed that 1 out 4 controls presented signs of progression from PTC to ATC (Fig. 6a) while none of the JPH203 treated animals presented ATC progression (Fig. 6b). We then analyzed tissue sections by immunofluorescence staining to quantify proliferation markers (Ki67, BrdU) and apoptosis marker TUNEL. The number of both Ki67(Fig. 6c) and BrdU-positive cells (Fig. 6d) were reduced in $\mathrm{JPH} 203$-treated mice (15\% and $17 \%$, respectively), however, this decrease was not statistically significant. On the other hand, we found a statistically significant elevation of TUNEL-positive bodies in JPH203-treated tumors $(p=0.032)$ compared to vehicle-treated tumors
(Fig. 6e). We then evaluated the JPH203 treatment efficiency in tumor cells in vivo. The transcription factor ATF5 has been shown to be highly transcriptionally upregulated in vitro when cells are cultured in the absence of leucine [35] and is widely accepted as indicator of the amino acid stress response. Interestingly, Atf5 transcript levels were significantly increased by 2.9 -fold in JPH203 -treated tumors (Fig. 6f). Finally we quantified the transcript levels of Slc7a8 encoding LAT2, which is functionally equivalent to LAT1, and its heavy chain Slc3a2. Importantly, both Slc7a8 and Slc3a2 transcripts were not altered in JPH203-treated tumors (Fig. 6g).

\section{LAT1 expression is significantly increased in human ATC and associated with a shorter survival of patients diagnosed with PTC}

To address the importance of LAT1 in human thyroid cancers, we obtained samples from patients, including non-cancerous thyroids, PTC and ATC. SLC7A5 transcription was significantly increased (4.9-fold) in the ATC group compared to normal tissues (Fig. 6a, $\mathrm{p}=$ 0.03). Similar to the mouse model, SLC7A5 transcription levels were intermediate in PTC samples (Fig. 7a).

To further investigate the potential role of LAT1 in patients, the TCGA PTC dataset containing 400 tumor samples with RNAseq and survival data was analyzed [36] using the cBioPortal online platform [37, 38]. A z-score threshold of 1 was used to define samples with 
A
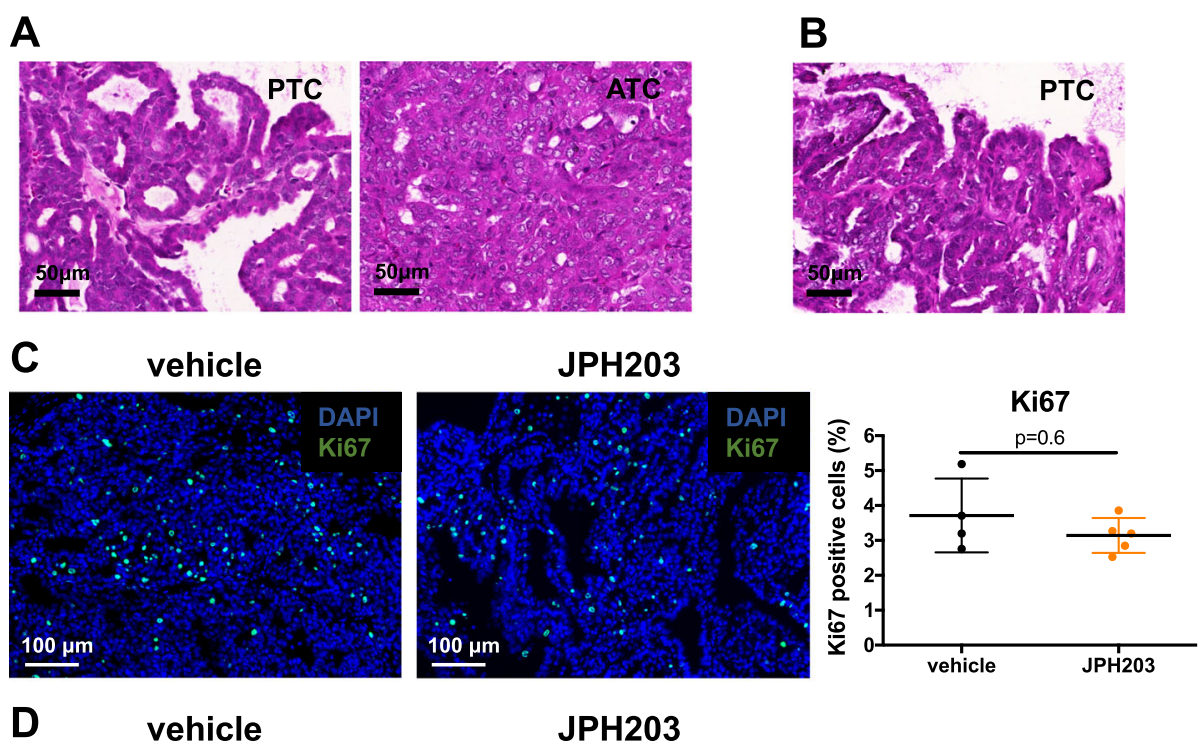

JPH203
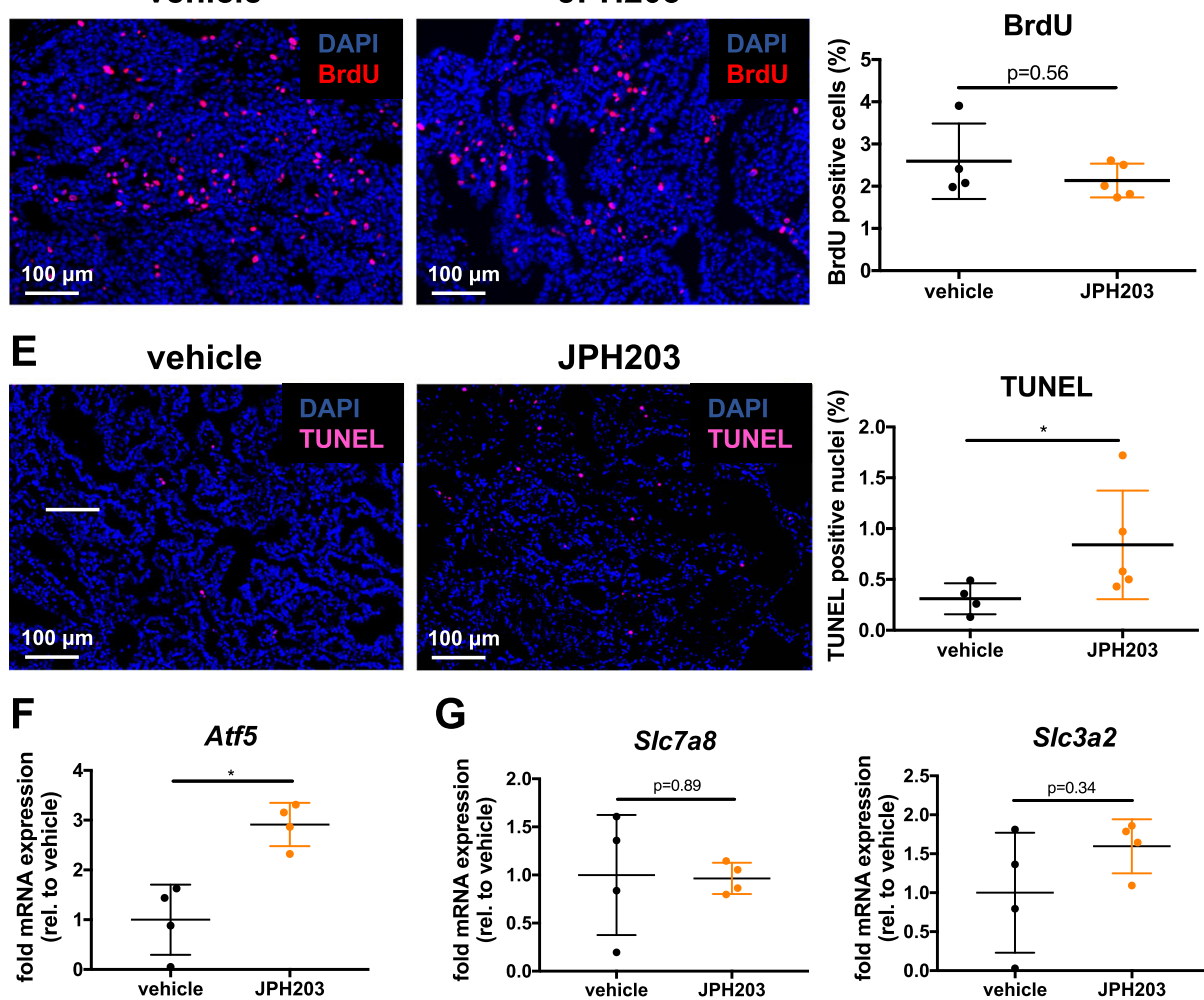

G
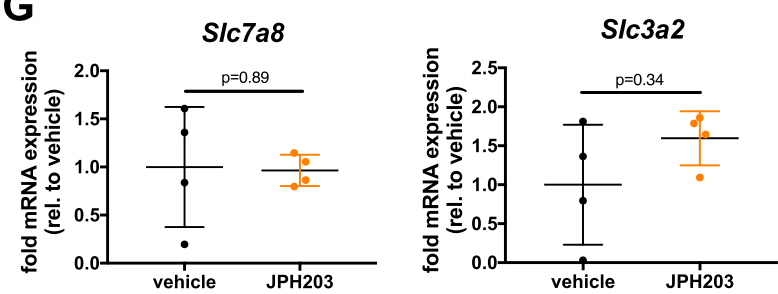

Fig. 6 Tumors of JPH203-treated mice exhibit an increase in TUNEL-positive nuclei and activation of the amino acid stress response. H\&E pictures demonstrating PTC/ATC features in (a) a vehicle-treated mouse and PTC features in (b) a JPH203-treated mouse. c, d Ki67-positive cells and BrdU-positive cells were quantified from each mouse and plotted in the graphs. e TUNEL-positive nuclei were quantified from each mouse and plotted in the graph. $\mathbf{f}, \mathbf{g}$ Atf5, S/c7a8 and S/c3a2 transcription levels were quantified in vehicle- and JPH203-treated animals. Transcription levels of each gene were normalized to Tubala and plotted as fold change relative to vehicle level. All statistical analyses were performed by using a two-tailed Mann-Whitney test

increased SLC7A5 transcription. Survival analysis by Kaplan-Meier estimate revealed that patients with high SLC7A5 had a median survival of 98 months, whereas the median survival of patients with lower SLC7A5 transcription was undefined (Fig. $6 \mathrm{~b}, p=0.0113$ ). Finally, we addressed whether transcript levels of the sodium iodide symporter (NIS, SLC5A5) were lower in the high SLC7A5 group, because low SLC5A5 levels were associated with radioiodine resistance [39]. Interestingly, there was a significant co-occurrence of SLC5A5 
A

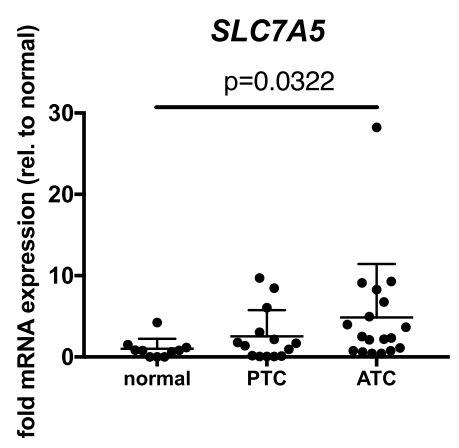

B

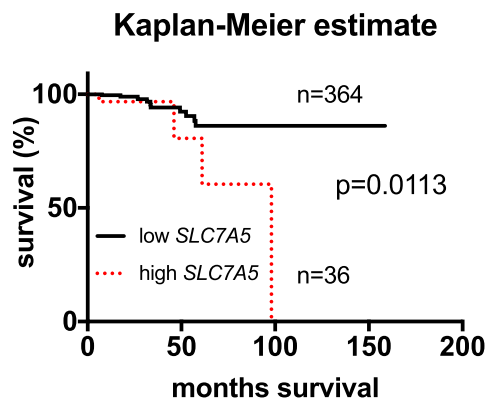

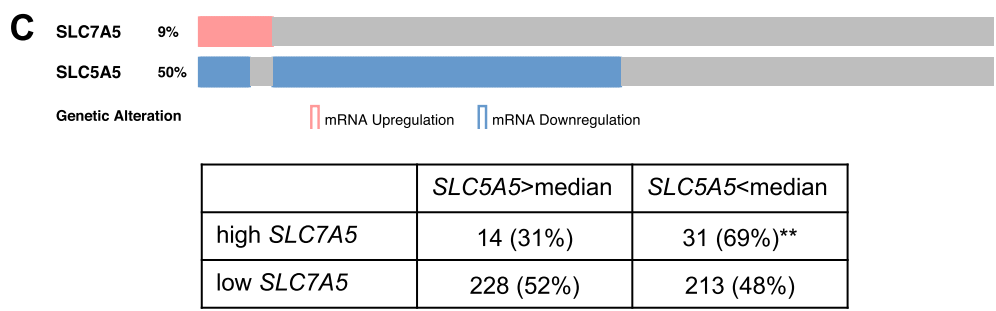

Fig. 7 LAT1 is upregulated in human ATC and associated with shorter survival in PTC patients. a SLC7A5 transcription levels were quantified in normal thyroid $(n=10)$, PTC $(n=14)$ and ATC $(n=18)$ samples derived from patients. Transcription levels of each gene were normalized to ACTB and plotted as fold change relative to normal thyroid. Statistical analysis was performed using a Kruskal-Wallis test with Dunn's correction for multiple comparisons, $p$-value is indicated. b The PTC dataset (TCGA, Cell 2014) containing 400 tumor samples with RNAseq and survival data was analyzed using the cBioPortal online platform. Z-score $>1$ was used to define samples with high SLC7A5 expression $(n=36)$ and $z$-score $<1$ was used to define samples with low SLC7A5 expression $(n=364)$. Statistical analysis was performed by using a log-rank test, $p$-value is indicated. c SLC5A5 expression levels were analyzed in the PTC dataset from (b) and co-occurrence of SLC5A5 downregulation (defined as expression $<$ median) with high SLC7A5 (z-score > 1) was quantified. Statistical analysis was performed by using a one-sided Fisher's exact test

downregulation with high SLC7A5 transcription (Fig. 7c, $p=0.006$ ). Furthermore we analysed two cohorts from the GEO NCBI portal containing ATC samples compared to non-tumoral tissues and/or PTC tissues. In both cases ATC tissues presented significantly elevated SLC7A5 transcription compared to normal tissues and PTC (Additional file 1: Figure S2).

\section{Discussion}

The increased metabolism that is observed in tumors requires elevated uptake of nutrients such as EAAs. The EAA transporter LAT1 (SLC7A5) might play a crucial role in this process, as it shows increased transcription and/or expression in various tumors versus normal tissues [40]. However, the evidence of a causal relationship between LAT1 expression and tumor growth has been addressed only in few reports [31, 41]. Additionally, downregulation of SLC7A5 by shRNAs inhibited growth of prostate [42] and gastric cancer cells [43], but did not affect proliferation of cholangiocarcinoma cells [44] or ovarian cancer cells [45]. Because of this apparent tissue specificity of LAT1 in tumors, we became interested in evaluating the role of this amino acid transporter in thyroid cancer in vitro and, more importantly, in vivo.
In experiments assessing the transcription levels of SLC7A5 by TaqMan qPCR in different thyroid cancer cell lines the prostate cancer cell line LNCaP was used as a negative control [46] and the colon cancer cell line HT-29, in which LAT1 is highly and functionally expressed at the plasma membrane [31] served as positive control. The expression of LAT1 in all thyroid cancer cell lines was detectable at various levels (Fig. 1a and b).

In order to use a suitable pharmacological tool we synthesized the selective LAT1 inhibitor JPH203, which is currently the only potent LAT1-specific inhibitor available. ${ }^{3} \mathrm{H}$-leucine uptake was reduced by $90 \%$ at concentrations of $1 \mu \mathrm{M} \mathrm{JPH} 203$ in the two ATC cell lines that were analyzed, which demonstrated the dominant role of LAT1-dependent leucine uptake in these cells (Fig. 1c). Our control cell line HT-29 presented the expected potent inhibition of leucine uptake by JPH203 that was similar to the inhibition in 8505c and SW1736, while leucine uptake was not affected by JPH203 in LNCaP cells lacking LAT1 expression (Additional file 1: Figure S1). Because the compound did not induce efflux of ${ }^{3} \mathrm{H}$-leucine, which is typically observed by substrates like tyrosine or leucine [32], but efficiently inhibited this process we conclude that 
JPH203 is a non-substrate inhibitor that likely is competitive. This is also supported by the fact that proliferation inhibition by JPH203 was only observed when the EAA concentration was reduced (Figs. 2e). This is consistent with the recently published report showing that in a leukemia model, the JPH203 anti-proliferative effect is reduced by addition of EAA but not by NEAA [41].

We cannot exclude minor LAT1 independent leucine uptake, as seen in LAT1 deleted LS174T cells that continue to grow in DMEM medium [47], but at low EAA concentrations the ATC cell lines were almost solely depending on LAT1 for their leucine uptake.

Blocking LAT1 by JPH203 reduced proliferation of 5 out of 6 thyroid cancer cells with relative $\mathrm{IG}_{50}$ ranging from $1.3 \mu \mathrm{M}$ to $6.8 \mu \mathrm{M}$. The PTC cell line $\mathrm{K} 1$ was less sensitive $(16.9 \mu \mathrm{M})$, reflecting the reduced LAT1 expression in this line. In agreement with these findings, JPH203 at concentrations below $15 \mu \mathrm{M}$ did not display any anti-proliferative effect on LNCaP cells with a relative $\mathrm{IG}_{50}$ calculated above $100 \mu \mathrm{M}$, while for HT-29 cells an $\mathrm{IG}_{50}$ of $4.1 \mu \mathrm{M}$ was reported [31]. Thus, only at full blockage of leucine uptake an anti-proliferative effect was seen. Although we cannot exclude any unspecific effects of JPH203 in ATC cell lines, the fact that JPH203 did not affect proliferation of LNCaP cells below $10 \mu \mathrm{M}$ indicates that off-target effects are unlikely at this concentration.

Nicklin et al. have well studied the relationship between LAT1-dependent leucine uptake and mTOR [3]. Here, we used Phospho-S6 and Phospho-p70S6K as readouts for mTORC1 activity and found a decrease of Phospho-S6 and Phospho-p70S6K levels in all JPH203 -treated thyroid cancer cells which indicates that mTORC1 activity is affected (Fig. 3). Interestingly we found that the ERK pathways was not negatively affected by the drug, and neither was AKT phosphorylation. This demonstrates the specificity of the drug and that the effect observed is not a general deterioration of the condition of the cells. mTORC1 alteration is consistent with a previous report, which showed that LAT1 inhibition by JPH203 reduced mTORC1 activity in T-cell lymphoma cells [41]. Apart from leukemia cells, blocking all LATs (LAT1-4) by $\mathrm{BCH}$ reduced mTORC1 activity in HeLa cells [3]. However, to our knowledge, this is the first report indicating that the specific inhibition of LAT1 by JPH203 affects mTORC1 in carcinoma cells. This suggests that LAT1 could be used to modulate mTORC1 in a tumor-specific manner, potentially avoiding the side effects of systemic mTOR inhibition.

Noteworthy, at low levels of EAA $(0.25 \times$ or $0.125 \times)$ the leucine concentration is closer to the physiological levels observed in plasma (Additional file 1: Table S1 and supplementary material of [33]. In order to translate the above observations to an in vivo situation we took advantage of a genetically engineered mouse model of thyroid cancer. In this model, which thyroid-specifically express $\mathrm{BRAF}^{\mathrm{V} 600 \mathrm{E}}$ and PIK3CA ${ }^{\mathrm{H} 1047 \mathrm{R}}$ mutations leading to constitutively active MAPK and Pi3'K pathways, it was previously demonstrated that 3-6 months after tamoxifen induction the tumors display both PTC and ATC features [27]. Based on this, we selected the four-months time point to start the JPH203 treatment to subsequently asses its effect on thyroid growth in late-stage disease. Slc7a5 transcription was increasing with tumor progression from wild-type to $\mathrm{BRAF}^{\mathrm{V} 600 \mathrm{E}}$ single-mutant tumors, which correspond to benign and PTC lesions, and $\mathrm{BRAF}^{\mathrm{V} 600 \mathrm{E}} / \mathrm{PIK} \mathrm{CA} \mathrm{A}^{\mathrm{H} 1047 \mathrm{R}}$ double-mutant tumors that consisted of PTC and ATC foci (Fig. 4a). Concomitantly, the transcription level of SLC7A5 was lower in the PTC cell line K1 when compared to the ATC cell lines $8505 \mathrm{c}$ and SW1736 (Fig. 1a). This is consistent with the fact that LAT1 is associated with invasive behavior of cancer cells $[48,49]$ and that ATC is a very invasive highly aggressive tumor subtype in which most patients are not suitable for surgery anymore due to local invasion at initial diagnosis [19]. Similarly to studies indicating that $4 \mathrm{~F} 2 \mathrm{hc}$ (SLC3A2) is overexpressed during the progression of breast and pancreatic cancer $[8,11]$, we detected significantly increased transcript levels of Slc3a2 in $\mathrm{BRAF}^{\mathrm{V} 600 \mathrm{E}} / \mathrm{PIK} \mathrm{CA}^{\mathrm{H} 1047 \mathrm{R}}$ double-mutant tumors (Fig. 4a). Our data indicate that 4F2hc expression increased in parallel with LAT1 in order to enhance LAT1 activity in thyroid cancer. Finally, we found that ASCT2 (Slc1a5), which works together with LAT1, was not altered in $\mathrm{BRAF}^{\mathrm{V} 600 \mathrm{E}}$ single-mutant tumors or $\mathrm{BRAF}^{\mathrm{V} 600 \mathrm{E}} / \mathrm{PIK} \mathrm{CA}^{\mathrm{H} 1047 \mathrm{R}}$ double-mutant tumors. However, in the $\mathrm{BRAF}^{\mathrm{V} 600 \mathrm{E}} / \mathrm{PIK} \mathrm{CA}^{\mathrm{H} 1047 \mathrm{R}}$ double-mutant tumors the functionally equivalent transporter Slc38a2 (SNAT2) was 2.2-fold increased, although not statistically significant it could still partially compensate the lack of increased Slc1a5 transcription (Fig. 4a). Thus, in this mouse model all the partners required for LAT1-dependent leucine uptake were transcribed and in some cases upregulated with tumor progression. Since c-MYC has been shown in the context of pancreatic cancer cells to drive SLC7A5 transcription [34], in our mouse model we have tested the relative role of the RAF-MEK-ERK and Pi3'K pathways for Slc7a5 transcription. MEK inhibition was very potent in reducing Slc7a5 transcripts while Pi3'K inhibition was not (Fig. 4b). This reflects the apparent predominant role of $\mathrm{BRAF}^{\mathrm{V} 600 \mathrm{E}}$ to induce LAT1 elevation. It was also worth noticing that while LNCaP cells were affected by EAA reduction, $8505 \mathrm{c}$ expressing LAT1 cells showed a resistance to this "amino acids starvation" (Fig. 2a and d). Importantly, JPH203 exposure restored "amino acids starvation" sensitivity in $8505 \mathrm{c}$ similarly to LNCaP cells. Furthermore amino acids concentration in blood and therefore in 
tissues are at similar levels as in our "amino acids starvation" condition (Additional file 1: Table S1). Taken together these date suggest that BRAF ${ }^{\mathrm{V} 600 \mathrm{E}}$ induces LAT1 elevations that confers tumor cells the ability to grow in the nutrient-limited environment.

To study the effect of LAT1 inhibition in thyroid cancer in vivo, mice were treated with a previously established effective dose of JPH203 at $50 \mathrm{mg} / \mathrm{kg}$ [41]. Oda et al. demonstrated that applying a dose of $25 \mathrm{mg} / \mathrm{kg}$ $\mathrm{JPH} 203$ in mice results in a plasma concentration of $2.4 \mu \mathrm{M}$ that is maintained during at least $4 \mathrm{~h}$ [31]. Therefore, we assumed that the $50 \mathrm{mg} / \mathrm{kg}$ dose could result in a plasma concentration, sufficient to block LAT1 according to our in vitro data (Fig. 1 and 2). Interestingly, treated-mice presented a cytostatic effect with a tumor growth arrest after 14 days of treatment and subsequent stable disease (Fig. 5c). Proliferation markers (Ki67, BrdU) were not significantly decreased in JPH203-treated tumors (Fig. 6c and d) while apoptosis was elevated as demonstrated by TUNEL staining (Fig. $6 \mathrm{e})$. This observation is compatible with mTOR inhibition that is often associated with increased apoptosis. The increase of apoptosis associated with no measurable modifications of tumor proliferation resulted in an apparent tumor size stabilization or "zero net gain". Importantly, the strong 2.9 -fold increase of Atf5 transcription in JPH203-treated tumors suggests that LAT1 inhibition depleted EAA concentration in tumor cells in vivo (Fig. 6f). The fact that Slc7a8, which is functionally equivalent to LAT1, was not transcriptionally upregulated in JPH203-treated tumors indicates that this transporter was not able to compensate for the lower LAT1 activity (Fig. 6g). For the most aggressive cases with a survival median of 5 months such effect would most likely translate into clinical benefit.

The increased Slc7a5 transcription found in the mouse model (Fig. 4a) is consistent with the findings in human ATC (Fig. 7a) underscoring that LAT1 could also be involved in human ATC tumors. In addition, in the dataset available at TCGA Data Portal, focusing on PTC [36] showed a significant difference in the 5 -year survival between patients with high and low SLC7A5 levels. The estimated long-term survival was significantly reduced for patients with high SLC7A5 transcript levels (Fig. 7b) even if the disease progression free analysis did not show any difference (data not shown). While these data have to be taken carefully, further analyses from GEO datasets $[50,51]$ showed SLC7A5 increase from normal tissue to PTC and ATC (Additional file 1: Figure. S2) emphasizing the fact that SLC7A5 is associated with the most aggressive untreatable cases of thyroid cancers. Finally, the finding of high SLC7A5 levels significantly co-occurring with low SLC5A5 transcripts (Fig. 7c) might indicate that LAT1 is associated with aggressive forms of thyroid cancer like RAI refractory PTC. This is in line with reports on prostate cancer, pancreatic cancer and neuroendocrine lung tumors, in which high LAT1 expression was correlated with poor survival $[7,10,11]$.

\section{Conclusions}

Our data show that LAT1 plays a critical role in tumor growth in mice and mTORC1 activity in human thyroid cancer cell lines, suggesting that LAT1 helps cells grow in the physiological environment that is low in amino acids. Additionally, using a genetically engineered mouse model that recapitulates the development of human ATC, we observed significant growth arrest when LAT1 was inhibited by the non-substrate LAT1 inhibitor JPH203. This is the first study to show the preclinical benefit of blocking LAT1 for solid tumor in immunocompetent mice. Finally, in human thyroid cancer patients, LAT1 expression levels seem to correlate with tumor progression, poorer outcome and radioiodine resistance. Therefore, LAT1 should be considered as a potential therapeutic target in the development of new anticancer drugs in the context of unresectable and non iodine-treatable thyroid cancers.

\section{Additional file}

Additional file 1: Figure S1. Leucine uptake in negative control cells LNCaP. Figure S2. LAT1 transcription levels in GSE datasets 65144 and 33630. Table S1. Comparison of the amino acid concentrations (in $\mu \mathrm{M}$ ) in different media versus plasma. (PDF $104 \mathrm{~kb}$ )

\section{Abbreviations}

ATC: Anaplastic thyroid carcinoma; EAA: Essential amino acids; LAT1: L-type amino acid transporter 1; NIS: Sodium iodide symporter; PTC: Papillary thyroid carcinoma; RAl: Radioactive iodine

\section{Acknowledgements}

Special thanks to Martin McMahon for the Braf ${ }^{C A}$ mice, and Wayne Phillips for the Pik3ca ${ }^{L A T}$ mice. Another special thanks to Prof. Engelhard, Dr. Deutsch and Dr. Benarafa for the vivarium at the Theodor Kocher Institute. Finally, Prof. Dimitrios Fotiadis for his leadership in the SLC7 project of the NCCRTransCure. Also, we would like to acknowledge the Microscopy Imaging Center of the University of Bern (MIC). Dr. Häfliger was enrolled in the Graduate School for Cellular and Biomedical Sciences (GCB) of the University of Bern during this study.

\section{Funding}

This work was supported by the Swiss National Science Foundation grant NCCR-TransCure. The lab of RPC is also supported by the Swiss National Foundation grant 31003A_149824/1.

Availability of data and materials

Correlation of SLC7A5 levels and survival of thyroid cancer patients was analyzed using the cBioPortal online platform (http://www.cbioportal.org).

\section{Authors' contributions}

PH, JG, MR, AS and RPC conducted experiments; PH, JG, MR, MSD, KHA, JG and RPC designed experiments and analyzed data; $\mathrm{PH}$ and RPC prepared the manuscript. All authors read and approved the final manuscript. 


\section{Ethics approval}

All animal experiments were in accordance with the Swiss animal welfare law and were approved by the local veterinary authority in Bern (license number: BE92/15). The use of patient samples obtained at the University Hospital of Bern (Inselspital) was approved by the Cantonal Ethics Committee Bern (ref. no. 200/2014).

\section{Consent for publication}

Not applicable.

\section{Competing interests}

The authors declare that they have no competing interests.

\section{Publisher's Note}

Springer Nature remains neutral with regard to jurisdictional claims in published maps and institutional affiliations.

\section{Author details}

'Institute of Biochemistry and Molecular Medicine, and Swiss National Center of Competence in Research (NCCR) TransCure, University of Bern, Bühlstrasse 28, CH-3012 Bern, Switzerland. ${ }^{2}$ Institute of Pharmaceutical Sciences, and Swiss National Center of Competence in Research (NCCR) TransCure, ETH Zürich, Vladimir-Prelog-Weg 4, CH-8093 Zürich, Switzerland. Institute of Pathology, University of Bern, Murtenstrasse 31, CH-3008 Bern, Switzerland. ${ }^{4}$ Present address: Herbert Irving Comprehensive Cancer Center, Columbia University Medical Center, New York, USA.

Received: 29 May 2018 Accepted: 11 September 2018 Published online: 21 September 2018

\section{References}

1. Hanahan D, Weinberg RA. Hallmarks of cancer: the next generation. Cell. 2011;144:646-74.

2. Kanai $Y$, Segawa $H$, Ki M, Uchino $H$, Takeda E, Endou $H$. Expression cloning and characterization of a transporter for large neutral amino acids activated by the heavy chain of 4F2 antigen (CD98). J Biol Chem. 1998;273:23629-32.

3. Nicklin $P$, Bergman $P$, Zhang B, Triantafellow E, Wang $H$, Nyfeler B, et al. Bidirectional transport of amino acids regulates mTOR and autophagy. Cell. 2009;136:521-34.

4. Mastroberardino L, Spindler B, Pfeiffer R, Skelly PJ, Loffing J, Shoemaker CB, et al. Amino-acid transport by heterodimers of 4F2hc/CD98 and members of a permease family. Nature. 1998;395:288-91.

5. Duelli R, Enerson BE, Gerhart DZ, Drewes LR. Expression of large amino acid transporter LAT1 in rat brain endothelium. J Cereb Blood Flow Metab. 2000; 20:1557-62.

6. Ritchie JW, Taylor PM. Role of the system $L$ permease LAT1 in amino acid and iodothyronine transport in placenta. Biochem J. 2001;356:719-25.

7. Sakata T, Ferdous G, Tsuruta T, Satoh T, Baba S, Muto T, et al. L-type aminoacid transporter 1 as a novel biomarker for high-grade malignancy in prostate cancer. Pathol Int. 2009;59:7-18.

8. Furuya M, Horiguchi J, Nakajima H, Kanai Y, Oyama T. Correlation of L-type amino acid transporter 1 and CD98 expression with triple negative breast cancer prognosis. Cancer Sci. 2012;103:382-9.

9. Ichinoe M, Mikami T, Yoshida T, Igawa I, Tsuruta T, Nakada N, et al. High expression of L-type amino-acid transporter 1 (LAT1) in gastric carcinomas: comparison with non-cancerous lesions. Pathol Int. 2011;61:281-9.

10. Kaira K, Oriuchi N, Imai H, Shimizu K, Yanagitani N, Sunaga N, et al. Expression of L-type amino acid transporter 1 (LAT1) in neuroendocrine tumors of the lung. Pathol Res Pract. 2008;204:553-61.

11. Kaira K, Sunose Y, Arakawa K, Ogawa T, Sunaga N, Shimizu K, et al. Prognostic significance of L-type amino-acid transporter 1 expression in surgically resected pancreatic cancer. Br J Cancer. 2012;107:632-8.

12. Namikawa M, Kakizaki S, Kaira K, Tojima H, Yamazaki Y, Horiguchi N, et al. Expression of amino acid transporters (LAT1, ASCT2 and xCT) as clinical significance in hepatocellular carcinoma. Hepatol Res. 2015;45:1014-22.

13. Toyoda M, Kaira K, Ohshima Y, Ishioka NS, Shino M, Sakakura K, et al. Prognostic significance of amino-acid transporter expression (LAT1, ASCT2, and $\mathrm{xCT}$ ) in surgically resected tongue cancer. $\mathrm{Br} J$ Cancer. 2014;110:2506-13.
14. Hassanein M, Hoeksema MD, Shiota M, Qian J, Harris BK, Chen H, et al. SLC1A5 mediates glutamine transport required for lung cancer cell growth and survival. Clin Cancer Res. 2013;19:560-70.

15. Davies L, Welch HG. Increasing incidence of thyroid cancer in the United States, 1973-2002. JAMA. 2006;295:2164-7.

16. Siegel RL, Miller KD, Jemal A. Cancer statistics. CA Cancer J Clin. 2016;66:7-30.

17. Hundahl SA, Fleming ID, Fremgen AM, Menck HR. A National Cancer Data Base report on 53,856 cases of thyroid carcinoma treated in the U.S., 19851995. Cancer. 1998:83:2638-48.

18. Rosário PW, Calsolari MR. Thyroid ablation with 1.1 GBq (30 mCi) iodine-131 in patients with papillary thyroid carcinoma at intermediate risk for recurrence. Thyroid. 2014;24:826-31.

19. Smallridge RC, Ain KB, Asa SL, Bible KC, Brierley JD, Burman KD, et al. American Thyroid Association guidelines for Management of Patients with anaplastic thyroid Cancer. Thyroid. 2012:22:1104-39.

20. Davies H, Bignell GR, Cox C, Stephens P, Edkins S, Clegg S, et al. Mutations of the BRAF gene in human cancer. Nature. 2002;417:949-54.

21. Xing M. BRAF mutation in thyroid cancer. Endocr Relat Cancer. 2005;12:245-62.

22. Dankort D, Filenova E, Collado M, Serrano M, Jones K, McMahon M. A new mouse model to explore the initiation, progression, and therapy of BRAFV600E-induced lung tumors. Genes Dev. 2007;21:379-84.

23. Dankort D, Curley DP, Cartlidge RA, Nelson B, Karnezis AN, Damsky WE Jr, et al. BrafV600E cooperates with Pten loss to induce metastatic melanoma. Nat Genet. 2009;41:544-52.

24. Collisson EA, Trejo CL, Silva JM, Gu S, Korkola JE, Heiser LM, et al. A central role for $\mathrm{RAF} \rightarrow \mathrm{MEK} \rightarrow \mathrm{ERK}$ signaling in the genesis of pancreatic ductal adenocarcinoma. Cancer Discov. 2012;2:685-93.

25. Charles RP, lezza G, Amendola E, Dankort D, McMahon M. Mutationally activated BRAFV600E elicits papillary thyroid cancer in the adult mouse. Cancer Res. 2011;71:3863-71.

26. García-Rostán G, Costa AM, Pereira-Castro I, Salvatore G, Hernandez R, Hermsem MJ, et al. Mutation of the PIK3CA gene in anaplastic thyroid cancer. Cancer Res. 2005;65:10199-207.

27. Charles RP, Silva J, lezza G, Phillips WA, McMahon M. Activating BRAF and PIK3CA mutations cooperate to promote anaplastic thyroid carcinogenesis. Mol Cancer Res. 2014;12:979-86.

28. Endou H, Kanai Y, Tsujihara K, Saito K. Aromatic Amino Acid Derivatives and Medicinal Compositions. US Pat. 7,345,068 B2, 2008.

29. Kinross KM, Montgomery KG, Kleinschmidt M, Waring P, Ivetac I, Tikoo A, et al. An activating Pik3ca mutation coupled with Pten loss is sufficient to initiate ovarian tumorigenesis in mice. J Clin Invest. 2012;122:553-7.

30. Elmokh O, Ruffieux-daidié D, Roelli MA, Stooss A, Phillips WA, Gertsch J, et al. Combined MEK and $\mathrm{Pi} 3$ ' -kinase inhibition reveals synergy in targeting thyroid cancer in vitro and in vivo. Oncotarget. 2017:8:24604-20.

31. Oda K, Hosoda N, Endo H, Saito K, Tsujihara K, Yamamura M, et al. L-type amino acid transporter 1 inhibitors inhibit tumor cell growth. Cancer Sci. 2010;101:173-9.

32. Kim DK, Kanai Y, Choi HW, Tangtrongsup S, Chairoungdua A, Babu E, et al, Characterization of the system $L$ amino acid transporter in T24 human bladder carcinoma cells. Biochim Biophys Acta. 2002;1565:112-21.

33. Miyagi $Y$, Higashiyama M, Gochi A, Akaike M, Ishikawa T, Miura T, et al. Plasma free amino acid profiling of five types of cancer patients and its application for early detection. PLoS One. 2011;6:e24143.

34. Keitaro H, Promsuk J, Hitoshi E, Naohiko A. C-Myc is crucial for the expression of LAT1 in MIA Paca-2 human pancreatic cancer cells. Oncol Rep. 2012;28:862-6.

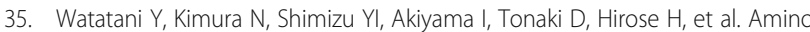
acid limitation induces expression of ATF5 mRNA at the post-transcriptional level. Life Sci. 2007;80:879-85.

36. Agrawal N, Akbani R, Aksoy BA, Ally A, Arachchi H, Asa SL, et al. Integrated genomic characterization of papillary thyroid carcinoma. Cell. 2014;159: 676-90.

37. Gao J, Aksoy BA, Dogrusoz U, Dresdner G, Gross B, Sumer SO, et al. Integrative analysis of complex Cancer genomics and clinical profiles using the cBioPortal. Sci Signal. 2013;6:pl1.

38. Cerami E, Gao J, Dogrusoz U, Gross BE, Sumer SO, Aksoy BA, et al. The cBio Cancer genomics portal: an open platform for exploring multidimensional cancer genomics data. Cancer Discov. 2012;2:401-4.

39. Chakravarty D, Santos E, Ryder M, Knauf JA, Liao X, West BL, et al. Smallmolecule MAPK inhibitors restore radioiodine incorporation in mouse thyroid cancers with conditional BRAF activation. 2011;121:4700-11. 
40. Wang Q, Holst J. L-type amino acid transport and cancer: targeting the mTORC1 pathway to inhibit neoplasia. Am J Cancer Res. 2015;5:1281-94.

41. Rosilio C, Nebout M, Imbert V, Griessinger E, Neffati Z, Benadiba J, et al. Ltype amino-acid transporter 1 (LAT1): a therapeutic target supporting growth and survival of T-cell lymphoblastic lymphoma/T-cell acute lymphoblastic leukemia. Leukemia. 2015;29:1253-66.

42. Wang Q, Tiffen J, Bailey CG, Lehman ML, Ritchie W, Fazli L, et al. Targeting amino acid transport in metastatic castration-resistant prostate cancer: effects on cell cycle, cell growth, and tumor development. J Natl Cancer Inst. 2013;105:1463-73.

43. Shi L, Luo W, Huang W, Huang S, Huang G, Lianghui S, et al. Downregulation of L-type amino acid transporter 1 expression inhibits the growth, migration and invasion of gastric cancer cells. Oncol Lett. 2013;6: $106-12$.

44. Janpipatkul K, Suksen K, Borwornpinyo S, Jearawiriyapaisarn N, Hongeng S, Piyachaturawat $P$, et al. Downregulation of LAT1 expression suppresses cholangiocarcinoma cell invasion and migration. Cell Signal. 2014;26:166879.

45. Fan X, Ross DD, Arakawa H, Ganapathy V, Tamai I, Nakanishi T. Impact of system $L$ amino acid transporter 1 (LAT1) on proliferation of human ovarian cancer cells: a possible target for combination therapy with anti-proliferative aminopeptidase inhibitors. Biochem Pharmacol. 2010:80:811-8.

46. Wang Q, Bailey CG, Ng C, Tiffen J, Thoeng A, Minhas V, et al. Androgen receptor and nutrient signaling pathways coordinate the demand for increased amino acid transport during prostate cancer progression. Cancer Res. 2011;71:7525-36.

47. Cormerais $Y$, Giuliano S, LeFloch R, Front B, Durivault J, Tambutté E, et al. Genetic disruption of the multifunctional CD98/LAT1 complex demonstrates the key role of essential amino acid transport in the control of mTORC1 and tumor growth. Cancer Res. 2016;76:4481-92.

48. Betsunoh H, Fukuda T, Anzai N, Nishihara D, Mizuno T, Yuki H, et al. Increased expression of system large amino acid transporter (LAT)-1 mRNA is associated with invasive potential and unfavorable prognosis of human clear cell renal cell carcinoma. BMC Cancer. 2013;13:509.

49. Kaira K, Oriuchi N, Imai H, Shimizu K, Yanagitani N, Sunaga N, et al. L-type amino acid transporter 1 and CD98 expression in primary and metastatic sites of human neoplasms. Cancer Sci. 2008:99:2380-6.

50. Tomas G, Tarabichi M, Gacquer D, Hebrant A, Dom G, Dumont JE, et al. A general method to derive robust organ-specific gene expression-based differentiation indices: application to thyroid cancer diagnostic. Oncogene. 2012;31:4490-8.

51. von Roemeling CA, Marlow LA, Pinkerton AB, Crist A, Miller J, Tun HW, et al. Aberrant lipid metabolism in anaplastic thyroid carcinoma reveals stearoyl CoA desaturase 1 as a novel therapeutic target. J Clin Endocrinol Metab. 2015;100:E697-709.

Ready to submit your research? Choose BMC and benefit from:

- fast, convenient online submission

- thorough peer review by experienced researchers in your field

- rapid publication on acceptance

- support for research data, including large and complex data types

- gold Open Access which fosters wider collaboration and increased citations

- maximum visibility for your research: over $100 \mathrm{M}$ website views per year

At $\mathrm{BMC}$, research is always in progress.

Learn more biomedcentral.com/submissions 